\title{
Artigos
}

\section{Autonomia e Práticas Integrativas e Complementares: significados e relações para usuários e profissionais da Atenção Primária à Saúde}

Autonomy and integrative and complementary practices: meanings and relations through the lens of Primary Health Care service users and professionals (abstract: p. 17)

Autonomía y Prácticas Integrativas y Complementarias: significados y relaciones para usuarios y profesionales de la Atención Primaria de la Salud (resumen: p. 17)

Léo Fernandes Pereira ${ }^{(a)}$

$<$ leo.fernandes.pereira@gmail.com>

Cassiano Ricardo Rech ${ }^{(\mathrm{b})}$

<cassiano.rech@ufsc.br> (D)

Simone Morini ${ }^{(c)}$

<simonemorini11@gmail.com>

\author{
(a) Pós-graduando do Programa \\ de Saúde Coletiva (doutorado) \\ Departamento de Saúde \\ Pública, Centro de Ciências da \\ Saúde, Universidade Federal \\ de Santa Catarina. Campus \\ Universitário Reitor João David \\ Ferreira Lima, s/n, Trindade. \\ Florianópolis, SC, Brasil. \\ 88040-900. \\ (b) Departamento de Educação \\ Física, Centro de Desportos, \\ Universidade Federal de \\ Santa Catarina. Florianópolis, \\ SC, Brasil. \\ (c) Secretaria Municipal de Saúde \\ de Florianópolis. Florianópolis, \\ SC, Brasil.
}

Este estudo investigou os significados de autonomia em saúde e de Práticas Integrativas e Complementares (PIC) atribuídos por usuários e profissionais de um Centro de Saúde (CS) e as possíveis contribuições das PIC para a autonomia do usuário. Foi realizada uma pesquisa qualitativa, cujas informações foram obtidas mediante entrevistas semiestruturadas, gravadas em áudio e interpretadas mediante análise de conteúdo. Participaram 18 indivíduos, entre frequentadores de um grupo de yoga, do serviço de acupuntura e profissionais de um CS de Florianópolis, Santa Catarina, Brasil. Os resultados revelaram entendimentos múltiplos sobre autonomia em saúde e diferenças entre as PIC investigadas, yoga e acupuntura, o que pareceu relacionado à primeira prática estar mais inserida na lógica da promoção da saúde que a segunda, mais restrita ao âmbito da clínica.

Palavras-chave: Autonomia. Práticas integrativas e complementares. Yoga. Acupuntura.

Pereira LF, Rech CR, Morini S. Autonomia e Práticas Integrativas e Complementares: significados e relações para usuários e profissionais da Atenção Primária à Saúde. Interface (Botucatu). 2021; 25: e200079 https://doi.org/10.1590/interface.200079 


\section{Introdução}

A autonomia é considerada um dos objetivos centrais do trabalho em saúde no âmbito do Sistema Único de Saúde (SUS). Entretanto, autores têm constatado que as práticas em saúde hegemônicas, atualmente baseadas no modelo biomédico, pouco têm contribuído para ampliação do grau de autonomia de pessoas e coletividades, o que justifica a procura da população por novas terapêuticas ${ }^{1-3}$.

Nesse cenário, o Ministério da Saúde (MS) aprovou, em 2006, a Política Nacional de Práticas Integrativas e Complementares (PNPIC) no intuito de promover o estímulo ao autocuidado e à autonomia da pessoa por meio da ampliação da oferta e da divulgação de práticas não convencionais em saúde ${ }^{4}$. No âmbito do Sistema Único de Saúde (SUS), essas técnicas e os sistemas de saúde, que são distintos da biomedicina, são denominados de Práticas Integrativas e Complementares (PIC). Em um estudo de revisão sistemática, observou-se que existe perspectiva de crescimento das PIC, pois elas trazem ganhos com custos relativamente baixos. Outros benefícios destacados pelo estudo são a maior qualidade de vida, a integração social e a busca de autonomia, em que o usuário é visto como um sujeito ativo 5 .

Entretanto, passada mais de uma década após sua implementação, observa-se um baixo conhecimento por parte de gestores, profissionais de saúde e da população a respeito dessa política pública ${ }^{6}$. Além disso, a recente expressão adotada pela PNPIC, Prática Integrativa e Complementar, levanta discussóes conceituais, pois tal nomenclatura abrange um conjunto muito heterogêneo de práticas que possuem características consideravelmente diversas ${ }^{7}$. Isso pode levar a generalizações sem fundamentação empírica, como a de que todas as PIC contribuem de maneira indistinta para a autonomia do usuário ${ }^{8}$ É possível que, dentro de uma mesma PIC, existam certos aspectos que mobilizam mais os potenciais de autonomia e outros, menos. A acupuntura, por exemplo, pode gerar uma relação de dependência da pessoa com a ação profissionalizada, no sentido de diminuir sua capacidade de manejar seus próprios problemas de saúde, apesar de poder ter um efeito redutor significativo no consumo de analgésicos? ${ }^{9}$ Vê-se aí a ambivalência da acupuntura na tensão entre autonomia e dependência, o que chama a atenção para a relevância da discussão também em relação a outras PIC.

De acordo com revisão de literatura de 2019, observa-se que ainda são escassas as pesquisas que analisam a divulgação das PIC ao longo do processo de implementação de sua política. Constata-se a falta de estudos brasileiros que explorem o potencial terapêutico das PIC, sendo raros aqueles que analisam seus efeitos na autonomia do usuário $^{10}$. No plano internacional já existem discussões mais adiantadas sobre o que denominam as Medicinas Alternativas e Complementares (expressão correlata às PIC) que exploram aspectos ambíguos e, por vezes, contraditórios entre as práticas em saúde consideradas holísticas na sua relação com o modelo biomédico e o processo de medicalização social ${ }^{11-13}$.

A discussão entre o processo de autonomia e as PIC é recente no campo da Saúde Coletiva brasileira e envolve exploraçôes conceituais em ambos os lados da equação. Porque também a autonomia, considerada um aspecto fundamental da saúde, pode ser compreendida sob diferentes perspectivas e significados. Diante disso, reformulamos uma questão levantada por Czeresnia ${ }^{14}$ para indagarmos: que concepçôes de autonomia 
as PIC promovem? Assim, o objetivo deste estudo foi investigar, com base no ponto de vista de usuários e profissionais de um CS de Florianópolis, SC: 1) as concepções sobre autonomia em saúde; 2) a apropriação da expressão PIC; e 3) as suas possíveis contribuições para a autonomia do usuário.

\section{Procedimentos metodológicos}

Trata-se de uma pesquisa qualitativa, elaborada pela perspectiva construcionista. Essa abordagem, que possui uma visão antiessencialista e relativista da realidade, concebe o conhecimento como uma construção social entre os atores envolvidos (no caso, pesquisador e entrevistado), mediada por categorias, convençốes e linguagem ${ }^{15}$.

O estudo foi desenvolvido em um CS de Florianópolis, Santa Catarina. A cidade possui $49 \mathrm{CS}$, distribuídos em quatro distritos sanitários, e $43 \mathrm{CS}$ desenvolvem as seguintes PIC: yoga; fitoterapia; acupuntura; reflexologia; qi gong e auriculoterapia ${ }^{16}$. O CS da pesquisa foi selecionado pois era o local sensível às PIC, que possuía aulas de yoga, sessões de acupuntura e auriculoterapia, bem como uma horta de fitoterápicos.

Foram selecionados para o estudo indivíduos que possuíam algum vínculo com as PIC, sendo: a) seis usuários das atividades de yoga; b) seis usuários do serviço de acupuntura; c) seis profissionais de saúde que atuavam na unidade. A seleção dos usuários de yoga deu-se mediante convite aberto durante as aulas, enquanto para os usuários de acupuntura a seleção ocorreu pela indicação dos médicos responsáveis. Em relação aos critérios de inclusão, foram selecionados usuários com um mínimo de duas participaçóes nas aulas de yoga ou nas sessóes de acupuntura nos últimos dois meses. Os profissionais selecionados para a pesquisa foram os que tinham maior experiência de atuação com as PIC (entre um e dez anos de experiência) e atuavam na unidade, ficando selecionados: quatro médicos; uma enfermeira e uma educadora física.

O levantamento das informaçóes foi realizado por meio de duas entrevistas com roteiros semiestruturados, sendo uma para os usuários e outra para os profissionais. As questóes dirigidas para os dois grupos buscavam compreender as concepçóes de autonomia, a autonomia em saúde, o significado das PIC e sua contribuição para a autonomia. Além disso, para os usuários, investigaram-se as concepçôes de autocuidado e suas práticas, assim como mudanças associadas à participação das PIC.

As entrevistas foram conduzidas e gravadas pelo pesquisador principal após a autorização dos entrevistados, mediante preenchimento de Termo de Consentimento Livre e Esclarecido (TCLE). As gravações foram posteriormente transcritas e analisadas a fim de identificar, nos enunciados, as atitudes, escolhas, impressóes e os significados dos sujeitos em relação ao fenômeno investigado. Para tanto, utilizou-se a Análise de Conteúdo baseada em Bardin, que lida com a articulação entre os arranjos semânticos e linguísticos e as estruturas psicológicas e sociológicas dos enunciados. A Análise de Conteúdo consiste em um conjunto de procedimentos sistemáticos e objetivos, voltados para a inferência de conhecimentos com base na análise de comunicaçôes, e estruturados nas seguintes etapas: a) organização da análise; b) codificação; c) categorização; d) tratamento dos resultados; e) interpretação dos resultados ${ }^{17}$. Para 
(e)

manter o sigilo das informações, os indivíduos foram identificados com os nomes fictícios de Ártemis, Alounos, Brígida, Esculápio, Peon e Belenus (profissionais), Durga, Parvati, Lakshmi, Kali, Hanuman e Sarasvati (yoga), Wei, Da Chan, Pi, Fei, Xi e Dan (acupuntura). As entrevistas foram realizadas no auditório do CS, durante seu horário de funcionamento, entre agosto e novembro de 2015.

Todos os procedimentos realizados no estudo foram aprovados pelo Comitê de Ética em Pesquisa sobre Seres Humanos da Universidade Federal de Santa Catarina, sob o número CAAE 46333815.7.0000.0121, e pela Secretaria Municipal de Saúde de Florianópolis.

\section{Resultados e discussão}

Participaram do estudo 18 indivíduos, sendo seis usuários das atividades de yoga, seis usuários do serviço de acupuntura e seis profissionais de saúde que atuavam no CS e possuíam algum vínculo com PIC. Os entrevistados tinham idade entre vinte e 82 anos, e a maior parte dos usuários eram mulheres (75\%) e a maioria dos profissionais, homens (66\%). Para a análise do conteúdo, os núcleos de sentido (excertos relevantes) extraídos com base na leitura das transcriçôes foram divididos em três eixos: análise das concepções de autonomia em saúde; análise da compreensão do significado das PIC; e análise da conexão entre autonomia e PIC. Os núcleos de sentido de cada eixo foram então agrupados em categorias e temas, expostos no Quadro 1 e discutidos a seguir. 
Quadro 1. Exemplos de falas dos participantes sobre os significados de autonomia em saúde, de PIC e da conexão entre as PIC e autonomia.

\begin{tabular}{|c|c|}
\hline Núcleos de sentido & Categorias \\
\hline \multicolumn{2}{|l|}{ Significados de autonomia em saúde } \\
\hline $\begin{array}{l}\text { "[...] é ficar mais consciente" - Sarasvati } \\
\text { "[...] autonomia tem muito a ver com autoconhecimento [...] com a pessoa se dar conta do que faz bem pra ela" - } \\
\text { Ártemis } \\
\text { "É o autoconhecimento. A pessoa estudar o que é bom pra ela na alimentação, pra buscar saúde. " - Alounos }\end{array}$ & $\begin{array}{l}\text { Autonomia como } \\
\text { ampliação da consciência }\end{array}$ \\
\hline $\begin{array}{l}\text { "[...] é você ser dono, talvez, da tua forma de viver, 'né,." - Lakshmi } \\
\text { "[...] acho que autonomia entra bastante numa questão de responsabilidade consigo mesmo. " - Belenus } \\
\text { "[...] autonomia 'pro' usuário, eu acho que é ele se empoderar mais [...]" - Péon }\end{array}$ & $\begin{array}{l}\text { Autonomia como a } \\
\text { capacidade de governar a } \\
\text { si mesmo }\end{array}$ \\
\hline $\begin{array}{l}\text { "[...] é independência no tratamento." - Dan } \\
\text { "[...] procurar não ficar tão arraigado no médico, na medicina. " - Sarasvati } \\
\text { "É não cair na dependência da medicina curativa formal e nem na dependência de outras pessoas. " - Hanuman }\end{array}$ & $\begin{array}{l}\text { Autonomia como } \\
\text { sinônimo de } \\
\text { independência }\end{array}$ \\
\hline $\begin{array}{l}\text { "Particularmente eu não tenho autonomia, a não ser que se eu tivesse um plano de saúde bom, aí eu teria } \\
\text { autonomia" - Wei } \\
\text { "[...] do ponto de vista populacional [...] é ter acesso ao sistema de saúde, seja público ou privado [...]" - Alounos }\end{array}$ & Autonomia como acesso \\
\hline \multicolumn{2}{|l|}{ Compreensão do significado de PIC } \\
\hline $\begin{array}{l}\text { "[...] uma outra forma de cura" - Fei } \\
\text { "Acredito que são práticas que derivam de outras racionalidades médicas [...]" - Belenus } \\
\text { "[...] são aquelas práticas em saúde que são integrais no sentido de não dependerem da medicina convencional } \\
\text { para existir [...] que tem seu próprio sistema de diagnose, tem seu próprio sistema de fisiologia, anatomo-patologia } \\
\text { e tratamento. As medicinas complementares são aquelas que complementam algum aspecto da nossa medicina } \\
\text { convencional [...]" - Alounos }\end{array}$ & $\begin{array}{l}\text { PIC como uma forma } \\
\text { diferente de cura, } \\
\text { prevenção e tratamento }\end{array}$ \\
\hline $\begin{array}{l}\text { "Uma maneira de prevenir doenças e proporcionar o bem-estar. Em grupos... por que é integrativo? Dentro da } \\
\text { comunidade... Professor e os próprios alunos... eu não sei exatamente." - Parvati } \\
\text { "É uma coisa pra ajudar nos planos de saúde, não sei como é, na medicina, alguma coisa..." - Kali } \\
\text { "Não entendo..." - Durga }\end{array}$ & $\begin{array}{l}\text { Apropriação do termo PIC } \\
\text { pela população }\end{array}$ \\
\hline \multicolumn{2}{|l|}{ Conexões entre PIC e autonomia } \\
\hline $\begin{array}{l}\text { "[...] me despertou essa coisa [...] do autocuidado [...]. Que talvez eu não precise ficar bitolada na acupuntura, talvez } \\
\text { eu possa fazer um bom alongamento [...]" - Fei } \\
\text { "[...] eu comecei a pensar, [...] que eu tenho que cuidar mais, que realmente eu tinha que ter um momento pra mim } \\
\text { e foi dali que começou a surgir mais a vontade de mudar minha vida [...]" - Da Chang } \\
\text { "Por eu estar fazendo acupuntura eu não preciso de remédio na minha vida, assim. Então eu acredito que seja } \\
\text { algo relacionado à autonomia. Não depender de tomar remédio pra dormir, que é o que eu estava esperando que } \\
\text { fosse acontecer." - Dan }\end{array}$ & $\begin{array}{l}\text { Mudança de hábitos e } \\
\text { alterações subjetivas }\end{array}$ \\
\hline $\begin{array}{l}\text { "[...] depois do yoga eu comecei a procurar uns vídeos na internet pra fazer um pouquinho em casa. Então, de vez } \\
\text { em quando eu pego o meu tapetinho e faço [...]" - Parvati } \\
\text { "[...] o yoga foi maravilhoso por isso, agora eu to a mil, estudando as coisas do oriente. Abriu um campo assim, } \\
\text { novo." - Lakshmi } \\
\text { "[...] a prática da yoga deixa a gente um pouco mais independente, mais, como é que se diz, segura de si." - Kali }\end{array}$ & $\begin{array}{l}\text { Estímulo à prática } \\
\text { independente e ao } \\
\text { empoderamento }\end{array}$ \\
\hline $\begin{array}{l}\text { "Espero aprender ainda com acupuntura. Então, por enquanto não posso dizer que aprendi não." - Wei } \\
\text { "[.... eu vejo as pessoas procurar acupuntura porque - "ah, hoje eu acordei, eu to com um pouquinho de dor aqui", } \\
\text { o cara fica duas horas sentado aqui, ele não quer acupuntura, ele quer conforto, entende? E esse tipo de conforto } \\
\text { o posto de saúde não tem que dar, porque o cara não precisa disso. Ele tá precisando de outras coisas que estão } \\
\text { por trás disso." - Hanuman }\end{array}$ & Fatores limitantes \\
\hline $\begin{array}{l}\text { "Então eu acho que as PIC no atual momento desencadeiam mudança de vida, mas elas nem sempre conseguem } \\
\text { ser a mudança. Eu acho que elas desencadeiam a pessoa a pensar." - Brigida }\end{array}$ & $\begin{array}{l}\text { As PIC na direção da } \\
\text { autonomia do usuário }\end{array}$ \\
\hline
\end{tabular}




\section{As concepções de autonomia em saúde}

Inicialmente, foram investigadas as concepções sobre autonomia em saúde. Os relatos trazidos pelos usuários possibilitaram a identificação de quatro categorias conceituais de autonomia, a saber: a) como ampliação da consciência; b) como a capacidade de governar a si mesmo; c) como independência; e d) como possibilidade de acesso aos serviços de saúde. O Quadro 1 apresenta exemplos de relatos para cada categoria analisada.

Na primeira categoria, os indivíduos atrelaram autonomia ao processo de conhecimento, sobretudo ao "conhecimento de si”. Algumas afirmaçôes feitas pelos entrevistados coincidiram com a ideia trazida por Campos ${ }^{1}$ de que o sujeito é autônomo quando conhece e reflete sobre si mesmo e sobre o mundo. Nas falas, o desenvolvimento da autonomia em saúde esteve associado ao conhecimento sobre os fatores que se relacionam com a saúde e as doenças, com o funcionamento do corpo e com a gestão do cuidado. Como relatado por um entrevistado:

[...] por exemplo, a pessoa alérgica, autonomia pra ela é entender da onde vem o alérgeno. (Alounos)

De maneira geral, existe nas PIC uma valorização pelo autoconhecimento 7 . Um entrevistado trouxe como exemplo o yoga, que possui uma observância denominada svadhyaya, que significa o processo de se auto-observar durante a prática. De forma semelhante, a Medicina Tradicional Chinesa (MTC) também incentiva a ampliação da consciência e um melhor relacionamento da pessoa com o seu meio ${ }^{18}$.

O sentido de autonomia como a "capacidade de governar a si mesmo" também foi identificado no discurso dos entrevistados, por meio de expressóes como "ser dono da forma de viver", "dono do próprio cuidado". Por exemplo:

[...] acho que autonomia na saúde é a pessoa se apropriar de si mesma no cuidado dela na saúde. Então ela ter consciência de que ela tem o papel, o papel é dela de cuidar de sua saúde [...] então acho que autonomia entra bastante numa questão de responsabilidade consigo mesmo. (Belenus)

De fato, segundo o dicionário Houaiss ${ }^{19}$ (p. 351), o termo autonomia significa “a capacidade de se autogovernar". A ideia de autogoverno, presente na própria etimologia da palavra autonomia (auto - próprio e nomos - regra, norma), está presente desde pensadores da Grécia antiga, como Platão e Aristóteles, até filósofos modernos, como Kant. Platão relacionou autonomia ao conceito de autodomínio - o processo de controle dos desejos por meio da razão humana ${ }^{20}$. A autonomia também estava associada ao conceito grego de felicidade (eudaimonia), a qual consistia na capacidade de o indivíduo decidir sobre suas próprias ações e sintetizada na prescrição "sê senhor de si”21. De forma correlata, essa prescrição também é encontrada na Índia antiga, no contexto da tradição védica, de onde o yoga emergiu, e na etimologia da palavra swami (mestre), que significa aquele que é dono de $\mathrm{si}^{22}$. 
$\mathrm{Na}$ fala dos usuários, a autonomia em saúde apareceu frequentemente vinculada à responsabilidade do indivíduo. Ao enfatizarem o indivíduo como sendo responsável por suas condiçóes de saúde, fatores macroestruturantes e causas situadas fora de sua governabilidade pouco apareceram nas falas. Assim como foi evidenciado nas entrevistas, teóricos da Saúde Coletiva têm identificado uma tendência comportamentalista dentro dos discursos da promoção da saúde ${ }^{23,24}$. Parte importante dos projetos de promoção à saúde tem dificuldade em superar o enfoque individualista, o que restringe suas açôes à regulação do corpo e da vida social e à criação de critérios que delimitam o sentido do viver saudável23.

No entanto, a atribuição da responsabilidade pessoal também nos remete à ideia de autoatenção, que diz respeito às práticas e representaçóes realizadas pelos próprios sujeitos ou grupo social para diagnosticar, explicar, controlar, curar e prevenir os processos que afetam a saúde, sem a intervenção direta e intencional de profissionais de saúde ${ }^{25}$. Nas entrevistas, observou-se um movimento de busca dos usuários por recursos próprios para interpretação e manuseio dos seus adoecimentos e sofrimentos vividos. Ao nosso ver, tal movimento significa uma mudança, na população, de um comportamento corrente que foi assimilado culturalmente, que é o de esperar do especialista e dos exames complementares a resolução de seus problemas em saúde ${ }^{26}$.

De forma semelhante, outro sentido de autonomia trazido pelos entrevistados esteve relacionado à "independência”. Nos relatos, a independência na saúde é tomada com relação aos serviços, profissionais e medicamentos. Um entrevistado esclarece:

É não cair na dependência da medicina curativa formal e nem na dependência de outras pessoas, 'pra' que tu permaneça vivo. (Hanuman)

No entanto, não se pode atribuir à noção de autonomia uma condição de independência absoluta ou sinônimo de autossuficiência ${ }^{10}$. Ao desenvolver o conceito de autonomia, Morin ${ }^{27}$ (p. 282) coloca que "quanto mais um sistema desenvolver sua complexidade, mais poderá desenvolver sua autonomia, mais dependências múltiplas terá”. Alinhado com o paradigma da complexidade, $\operatorname{Campos}^{1}$ (p. 670) define autonomia como "a capacidade do sujeito de lidar com a sua rede de dependências". Essas definiçốes se opóem a uma visão simplificadora de autonomia isenta de dependências, assumindo o paradoxo de que a autonomia só pode ser concebida em relação à ideia de dependência ${ }^{27}$. Desse modo, considera-se que a autonomia é co-construída, ou seja, depende de capacidades e forças oriundas do próprio sujeito associadas às condiçôes externas a ele, como leis naturais, ordem social, relaçóes de poder e cultura. De acordo com Campos ${ }^{1}$, a autonomia não é vista como um estado estático, absoluto, mas como um processo dinâmico, sendo mais apropriado, assim, adotar expressóes como "coeficiente/graus de autonomia".

Conforme os relatos, constatou-se que "novas dependências" vêm sendo utilizadas na Atenção à Saúde. Quando perguntado - "quais formas e recursos você utiliza para realizar o seu cuidado em saúde?”, um usuário respondeu:

O meu [recurso]? Então, Google! (Dan) 
De acordo com a noção de autonomia trazida por Morin ${ }^{27}$, a internet pode ser considerada uma "dependência autonomizadora em saúde" significativa dos dias atuais. Basta constatar a quantidade de pessoas que praticam atividades físicas, como yoga, orientados por canais do Youtube, compram e buscam informaçóes sobre suplementos, medicamentos, diagnósticos e termos médicos em sites e nos mecanismos de procura, compartilham suas experiências e condições de saúde em fóruns virtuais. De forma geral, a vantagem da internet, no que diz respeito à autonomia na saúde, está na democratização da informação e na possibilidade de tomar decisões com maior liberdade de escolha ${ }^{28}$. Entretanto, por mais que a internet ofereça diferentes tipos de informações, entende-se que a construção da autonomia também envolve a capacidade crítica de mediar os dados, compreendendo que o sujeito se torna autônomo com o conhecimento, e não somente com informações.

Por fim, autonomia em saúde também foi apontada por parte dos entrevistados como a possibilidade de "acesso a serviços de saúde” de qualidade, considerando assim a saúde na sua dimensão político-institucional. Nas palavras de um entrevistado:

Então, autonomia do ponto de vista populacional [...] é ter acesso ao sistema de saúde, seja público ou privado, que funcione, que a pessoa consiga trazer suas demandas [...] (Alounos)

Essa colocação, coerente com o entendimento de que "o acesso limitado às estruturas políticas mina as bases da autodeterminação" 29 , aponta o fato de que a construção da autonomia não consiste somente em aumentar a capacidade do sujeito para agir sobre si mesmo, mas também em compreender e agir sobre o contexto, conforme objetivos democraticamente estabelecidos ${ }^{1}$. Nesse sentido, os Conselhos e Conferências de Saúde são espaços privilegiados para o exercício da autonomia, por meio da participação e do controle social sobre a implementação das políticas de saúde nas instâncias públicas. No entanto, o que se observa é que essas instâncias não estão sendo aproveitadas na sua plenitude pela população. Contribui para isso a falta da divulgação de informaçôes, aliada à existência de interesses múltiplos, fazendo que a população desconheça seu poder decisório sobre as políticas em saúde ${ }^{30}$.

No geral, os sentidos de autonomia em saúde trazidos pelos usuários apresentaram diferentes aspectos, mas convergentes para o conceito filosófico de autonomia. O que não pôde ser constatado foram sentidos que se aproximassem da abordagem complexa de Morin e Campos ${ }^{1,27}$, na qual as dependências teriam, na verdade, papel fundamental na construção da autonomia. 


\section{A compreensão do significado de PIC}

Quanto ao significado de PIC, grande parte dos entrevistados apresentou uma variedade de sentidos difusos, evidenciando a pouca apropriação dessa expressão pelos usuários. Essa ocorrência é justificada pelo fato de o termo ser uma denominação recente, adotada pelo MS, como expõe um entrevistado durante sua definição de PIC:

[...] isso [o termo PIC] é um aspecto normativo. (Esculápio)

A definição conceitual dessas práticas apresenta um certo desafio, tendo em vista a multiplicidade de cosmologias, doutrinas médicas e princípios terapêuticos que as compóem ${ }^{31}$. Diante da diversidade de nomenclatura utilizada para designar essas práticas, teóricos da Saúde Coletiva estão desenvolvendo uma categoria denominada "racionalidades médicas" 32 , que serve para estudos comparativos entre os diferentes sistemas médicos existentes nas variadas culturas do mundo. A racionalidade médica supóe um sistema complexo, estruturado em seis dimensóes fundamentais: cosmologia; doutrina médica (explicação do que é doença ou adoecimento, sua origem ou causa, evolução ou cura); morfologia (anatomia para a biomedicina); dinâmica vital (fisiologia); sistema de diagnose (recursos e raciocínio para o diagnóstico); e sistema de intervençôes terapêuticas (recursos e raciocínio para cura e tratamento) ${ }^{33}$. De acordo com essa perspectiva, sistemas médicos, como a MTC, "mostram-se como portadores de razão médica e de eficácia terapêutica próprias, coerentes com seu estilo de pensamento, contradizendo o senso comum de que somente a biomedicina seria portadora de racionalidade” (p.196) ${ }^{3}$. De maneira simples, um entrevistado sintetiza:

Não existe medicina alternativa, existem alternativas para a medicina. (Hanuman)

Formalmente, a expressão PIC define-se em relação ao modelo hegemônico em saúde ${ }^{31}$. Práticas complementares são aquelas usadas na prática biomédica e as integrativas são aquelas utilizadas de forma coordenada à biomedicina, baseadas em avaliaçóes científicas de segurança e eficácia de boa qualidade ${ }^{34}$. Tal definição não esteve presente nas falas dos usuários, que ainda utilizam a expressão "medicina alternativa” para designar as práticas e os saberes que são distintos da biomedicina.

Já os profissionais conceituaram a expressão PIC de maneira mais alinhada com os discursos oficializados. O conhecimento desses profissionais reflete a atual política municipal de apoio às PIC, que incentiva e proporciona aos profissionais de saúde oficinas de sensibilização e cursos introdutórios em diferentes PIC, como yoga, acupuntura e auriculoterapia. 


\section{As possíveis conexões entre as PIC e a autonomia do usuário}

As duas práticas investigadas na pesquisa, yoga e acupuntura, possuem finalidades distintas em relação à Atenção à Saúde, estando a primeira, de modo geral, mais vinculada ao campo da promoção de saúde e a segunda mais associada ao âmbito do tratamento. Reforça essa distinção o fato de as aulas de yoga serem coletivas e os atendimentos de acupuntura, individuais, o que faz os usuários terem visões distintas sobre essas práticas no contexto da Atenção Primária à Saúde (APS). A acupuntura é considerada um ramo da MTC, que consiste em introduzir agulhas metálicas em pontos precisos do corpo de um paciente para tratar diferentes males ou para provocar efeito anestésico ${ }^{19}$. Já o yoga é definido por um conjunto de práticas sistemáticas, que, partindo de ensinamentos filosóficos indianos, envolvem exercícios psicof ísicos, como alongamentos e respiraçôes ${ }^{19}$. No estudo, constatou-se que essas duas PIC são procuradas por pessoas que sofrem de problemas semelhantes, como dores osteomusculares e problemas do sistema nervoso e/ou emocionais, como estresse, ansiedade e insônia. No entanto, o fato de a acupuntura ser um tratamento em que o sujeito é visto como um paciente, e no yoga o sujeito ser entendido como um praticante, portanto mais ativo, faz que haja diferenças fundamentais entre a relação dessas práticas e a autonomia na saúde.

De acordo com as entrevistas foi possível identificar quatro temas relacionados às PIC e à autonomia do usuário: a) mudança de hábitos e alteraçôes subjetivas; b) estímulo à prática independente e ao empoderamento; c) fatores limitantes; d) as PIC na direção da autonomia do usuário.

O primeiro tema, "mudança de hábitos e alteraçôes subjetivas", foi identificado nas falas tanto dos usuários de yoga quanto dos de acupuntura. Em relação aos usuários de acupuntura, foram relatadas alteraçóes como: maior atenção para a respiração e para o autocuidado; melhora na qualidade do sono e aumento do bem-estar geral. A prática da respiração consciente, presente nas tradiçóes orientais, foi relatada por uma paciente como um importante recurso, resgatada após o início das sessóes de acupuntura:

[...] o eu suportar, eu ter essa resiliência pra suportar as dores que eu tenho sentido, que pra mim têm sido muitas, acho que pra mim tem a ver com a respiração, assim. É tirar o foco daquilo, um momento de aceitar aquilo que tu tá passando, que não é uma coisa pro resto da vida, é uma coisa temporária, momentânea, é resultado de algo. (PI)

Verificou-se que os benefícios observados não foram somente respostas orgânicas à técnica terapêutica do agulhamento, mas também consequência da relação dialógica estabelecida entre profissional e usuário. Isso confirma a posição de autores ${ }^{3}$ que afirmam que as PIC, em geral, usam da ressignificação da relação entre curador e paciente como elemento fundamental da terapêutica. Os usuários de yoga relataram alterações semelhantes, incluindo: menor agitação; melhora na qualidade do sono e na evacuação; maior disposição física e bem-estar geral; maior atenção para autocuidados como hidratação e alimentação; e maior sensação de pertencimento social. 
Outro tema que surgiu com as entrevistas foi o "estímulo à prática independente e empoderamento". A maioria dos usuários de yoga relata ter começado a praticar em casa alguns exercícios do yoga, como meditação e posturas físicas, após o início das aulas. Em relação aos usuários de acupuntura, a prática autônoma do agulhamento não foi considerada uma possibilidade, e também não relataram incluir em suas rotinas o uso de técnicas similares e mais acessíveis, como digitopressura e reflexologia, após o início do tratamento. No entanto, ambas as práticas incentivaram, no geral, uma postura mais ativa por parte do usuário, ampliando a conscientização e a responsabilidade em relação à própria saúde.

O terceiro tema para discussão, "fatores limitantes”, foi construído mediante algumas objeçốes que usuários e profissionais fizeram sobre a possível contribuição das PIC para a autonomia do usuário. A acupuntura foi apontada pelos profissionais como sendo uma ferramenta profissional-dependente. E como esclarece um entrevistado:

Toda prática que depende de um profissional, eu acho que vai limitar a minha autonomia. Porque vai depender do acesso que eu tenho àquele profissional. (Esculápio)

Nos atendimentos de acupuntura poderiam estar presentes outros recursos $\mathrm{da}$ MTC possíveis de serem praticados de forma independente, como digitopressura, reflexologia e exercícios de chi kung. Assim, constata-se a importância de reconectar a acupuntura à dimensão maior da MTC para que o seu potencial para a promoção da saúde não fique apenas limitado ao agulhamento de condições patológicas específicas. Uma entrevistada esclarece:

[...] a acupuntura, por exemplo, eu acho que ela é uma mudança de todo o olhar, para aquele paciente, de tudo, ela é um outro tipo de medicina, de cuidado, que não tem nada a ver com o cuidado ocidental. Então eu vejo hoje assim um pouco raso, às vezes, a gente tentando colocar a acupuntura na assistência como um remédio alopático. (Brigida)

De fato, autores se preocupam com o risco que a acupuntura corre de ter alguns de seus aspectos essenciais desvalorizados na prática clínica à medida que é absorvida pela racionalidade biomédica ${ }^{35}$. Da mesma forma, a aculturação do yoga também tem sido motivo de preocupação entre os especialistas da área ${ }^{36}$, que questionam novas ideologias do yoga que surgem no mercado, desprovidas de atributos e valores que são essenciais para sua caracterização. Parece que o yoga inserido no SUS goza de uma situação mais favorável à sua preservação por não sofrer diretamente os ditames do mercado, mas ainda assim tem-se o risco de vê-lo reduzido a uma "prática complementar” de exercícios psicofísicos. Assim, no processo de ocidentalização, as PIC vão "transformando-se em procedimentos especializados mais ou menos desligados de seu contexto cultural tradicional e de suas racionalidades originais, bem como dos valores solidários e 'empoderadores' caros à promoção da saúde”7 (p. 1740). 
O último tema, "as PIC na direção da autonomia do usuário", foi concebido com base nos comentários dos profissionais entrevistados sobre como as PIC promovem ou poderiam promover a autonomia do usuário e quais as que se dirigiriam mais para esse sentido. Assim, os entrevistados enfatizaram práticas que os usuários poderiam realizar em casa, como: fitoterapia; meditação; reflexologia; e práticas corporais como lian gong, yoga e biodança. Segundo um profissional entrevistado, a fitoterapia é uma prática reconhecidamente promotora de autonomia, já que responsabiliza o usuário pela sua própria produção de fármacos. Outras PIC sugeridas pelos profissionais, como meditação e lian gong por compartilharem do paradigma vitalista, oferecem técnicas particularmente promotoras de saúde por estimularem potenciais de cura autóctones, diminuindo, assim, a necessidade de cuidados externos e contribuindo para uma maior corresponsabilidade do sujeito na produção de sua saúde 7 .

Por meio das falas, verificou-se que as duas PIC observadas induzem à autonomia, visto que: ampliam o leque de terapêuticas ofertadas, oferecendo possibilidades de escolha; aumentam o grau de corresponsabilização do indivíduo por sua saúde; qualificam a relação profissional-usuário; transmitem conhecimentos sobre fatores que incidem no modo de vida e saberes relacionados ao autocuidado; incentivam a prática pessoal e independente; desencadeiam mudanças de hábitos; e melhoram a condição fisico-psíquica, aperfeiçoando assim a capacidade reflexiva. No yoga, a promoção da autonomia esteve mais relacionada ao incentivo dado à prática pessoal e independente. Já na acupuntura, a promoção da autonomia esteve mais sensível à forma de condução da consulta e ao perfil do profissional (o que não se restringe a esse tipo de atendimento) do que propriamente a sua técnica específica. Como também verificado em outras pesquisas, constata-se que a consulta de acupuntura facilita, mas não garante, que os profissionais adotem uma atitude profissional que estimule uma postura mais ativa dos usuários ${ }^{37}$. Ao possibilitarem o desenvolvimento do vínculo e de uma comunicação mais aberta entre profissional e usuário, ambas as PIC investigadas trilham na mesma direção.

Embora as dimensóes social e política da autonomia não tenham tido maior expressão no estudo, visto que a maioria dos entrevistados focou em aspectos individuais e comportamentais, as entrevistas mostraram que as PIC também ajudam a transformar o ambiente social (o clima) do CS. São geradas "múltiplas práticas de atitude", conforme uma entrevistada, que envolvem as organizaçôes informais entre os participantes, o compartilhamento de experiências na sala de espera, os atos de atenção e retribuição dos usuários para os profissionais e a aplicação de PIC entre os profissionais e servidores do CS. 


\section{Considerações finais}

A pesquisa teve por objetivo investigar os significados de autonomia em saúde e de PIC atribuídos por usuários e profissionais de um CS e as possíveis contribuiçóes das PIC para a autonomia do usuário. A pesquisa mostrou que os entrevistados relacionam autonomia em saúde com a aquisição de novos conhecimentos, maior autogoverno, independência e acesso aos serviços de saúde. Em relação ao significado de PIC, os usuários apresentaram definições diversas, evidenciando o desconhecimento do termo pela população. Já entre os profissionais, constatou-se que o significado atribuído ao termo está mais próximo do discurso da PNPIC.

Observou-se, ainda, que, na concepção dos usuários e profissionais, ambas as PIC investigadas influenciam positivamente a autonomia do usuário. No entanto, diferenças foram encontradas, aparentemente relacionadas ao yoga estar mais inserido na lógica da promoção da saúde que a acupuntura, mais restrita ao âmbito da clínica. Constatou-se que o yoga proporciona mais condiçóes para que o sujeito busque seus próprios recursos em saúde, uma vez que o usuário, como praticante, aprende os elementos dos quais se apropria. Como o yoga tem como tema central a emancipação do ser humano, acaba por transmitir uma perspectiva de saúde mais ampla do que somente a ausência de doenças ou sintomas, refletindo também sobre a saúde dos pontos de vista ético, ecológico e espiritual.

Já a acupuntura, apesar de fazer parte de um sistema médico complexo, que também traz em sua filosofia recursos favoráveis à autonomia do sujeito, no contexto em que está inserida, focada no tratamento de disfunçóes e patologias à luz da racionalidade biomédica, corre o risco de ter sua integralidade comprometida, e, junto com ela, a possibilidade de maior contribuição para a autonomia do usuário. Para isso, reitera-se a variedade de recursos da MTC, como a digitopressura, a reflexologia e os exercícios de chi kung, que promovam a saúde do usuário. A inclusão dessas outras técnicas no âmbito da APS poderia contribuir para o reconhecimento do usuário como sujeito autônomo, envolvido na produção de sua saúde, e não somente como um "paciente de acupuntura”, a depender pontualmente do tratamento clínico. 


\section{Contribuições dos autores}

Todos os autores participaram ativamente de todas as etapas de elaboração do manuscrito.

\section{Financiamento}

Esta pesquisa recebeu financiamento mediante bolsa concedida pelo Ministério da Saúde do Programa de Residência Multiprofissional em Saúde da Família da Universidade Federal de Santa Catarina.

\section{Agradecimentos}

Aos professores responsáveis pela disciplina de Oficina de Artigos Científicos, Eleonora d'Orsi e Marco Peres, promovida pelo Print/Capes UFSC e colegas participantes.

\section{Conflito de interesse}

Os autores não têm conflito de interesse a declarar.

\section{Direitos autorais}

Este artigo está licenciado sob a Licença Internacional Creative Commons 4.0, tipo BY (https://creativecommons.org/licenses/by/4.0/deed.pt_BR).

\section{(cc) BY}

\section{Editora}

Denise Martin

Editora associada

Fatima Corrêa Oliver

\section{Submetido em}

27/02/20

Aprovado em

$08 / 12 / 20$

\section{Referências}

1. Campos GW, Onocko R. Co-construção de autonomia: o sujeito em questão. In: Campos G, organizador. Tratado de saúde coletiva. São Paulo: Hucitec; 2006. p. 669-88.

2. Souza EF, Luz MT. Bases socioculturais das práticas terapêuticas alternativas. Hist Cienc Saude Manguinhos. 2009; 16(2):393-405.

3. Tesser CD, Barros NF. Medicalização social e medicina alternativa e complementar: pluralização terapêutica do Sistema Único de Saúde. Rev Saude Publica. 2008; 42(5):914-20. 
4. Brasil. Ministério da Saúde. Secretaria de Atenção à Saúde. Departamento de Atenção Básica. Política Nacional de Práticas Integrativas e Complementares no SUS - PNPICSUS. Brasília: Ministério da Saúde; 2006.

5. Monteiro MMS. Práticas integrativas e complementares no Brasil-Revisão sistemática [trabalho de conclusão de curso]. Recife: Centro de Pesquisas Aggeu Magalhães, Fiocruz; 2012.

6. Silva ASP, Feitosa ST. Revisão sistemática evidencia baixo nível de conhecimento acerca da política nacional de práticas integrativas e complementares por parte de gestores e profissionais da saúde. Rev Cienc Saude. 2018; 30(1):105-14.

7. Tesser CD. Práticas complementares, racionalidades médicas e promoção da saúde: contribuiçôes poucos exploradas. Cad Saude Publica. 2009; 25(8):1732-42.

8. Dallegrave D, Tesser CD. Práticas integrativas e complementares em saúde e medicalização social: indefinições, riscos e potências na atenção primária à saúde. Cad Saude Publica. 2020; 36(9):1-14.

9. Silva EDC, Tesser CD. Experiência de pacientes com acupuntura no Sistema Único de Saúde em diferentes ambientes de cuidado e (des)medicalização social. Cad Saude Publica. 2013; 29(11):2186-96.

10. Ruela LDO, Moura CDC, Gradim CVC, Stefanello J, Iunes DH, Prado RRD. Implementação, acesso e uso das práticas integrativas e complementares no sistema único de saúde: revisão da literatura. Cienc Saude Colet. 2019; 24(11):4239-50.

11. Ning A. How 'Alternative' is CAM? Rethinking conventional dichotomies between biomedicine and Complementary/Alternative Medicine. Health. 2012; 17(2):135-58.

12. Lowenberg J, Davis F. Beyond medicalisation-demedicalisation: the case of holistic health. Sociol Health Illn. 1994; 16(5):579-99.

13. Scott A. Paradoxes of holism: some problems in developing an anti-oppressive medical practice. Health. 1999; 3(2):131-49.

14. Czeresnia D. O conceito de saúde e a diferença entre prevenção e promoção. In: Czeresnia D, De Freitas CM, organizadores. Promoção da saúde: conceitos, reflexões, tendências. Rio de Janeiro: Fiocruz; 2003. p. 39-53.

15. Spink MJ, organizadora. Práticas discursivas e produção de sentidos no cotidiano: aproximaçóes teóricas e metodológicas. Rio de Janeiro: Centro Edelstein de pesquisas sociais; 2013.

16. Florianópolis. Secretaria Municipal de Saúde. As Práticas Integrativas e Complementares em Florianópolis no período de 2010-2015. Apresentação da Comissão para implantação das PIC de Florianópolis. Florianópolis: Secretaria Municipal de Saúde; 2015.

17. Bardin L. Análise de conteúdo. 3a ed. Lisboa: Ediçôes 70; 2004.

18. Telesi EJ, Silva K, Cabral M. Caderno temático da Medicina Tradicional Chinesa. São Paulo: Secretaria Municipal da Saúde; 2002.

19. Houaiss A. Dicionário Houaiss da língua portuguesa. Rio de Janeiro: Objetiva; 2009.

20. Zatti V. Autonomia e educação em Immanuel Kant \& Paulo Freire. Porto Alegre: EDIPUCRS; 2007.

21. Fleury-Teixeira P, Vaz FAC, Campos F, Álvares J, Aguiar RAT, Oliveira VA. Autonomia como categoria central no conceito de promoção de saúde. Cienc Saude Colet. 2008; 13 Supl 2:2115-22. 
22. Feuerstein G. Enciclopédia de yoga da pensamento. São Paulo: Editora Pensamento; 1997.

23. Carvalho $S R$. As contradições da promoção à saúde em relação à produção de sujeitos e a mudança social. Cienc Saude Colet. 2004; 9(3):669-78.

24. Verdi M, Caponi S. Reflexốes sobre a promoção da saúde numa perspectiva bioética. Texto Contexto Enferm. 2005; 14(1):82-8.

25. Menéndez E. Modelos de atención de los padecimientos: de exclusiones teóricas y articulaciones prácticas. Cienc Saude Colet. 2003; 8(1):185-207.

26. Tesser CD. Medicalização social (I): o excessivo sucesso do epistemicídio moderno na saúde. Interface (Botucatu). 2006; 10(19):61-76.

27. Morin E. Ciência com consciência. Rio de Janeiro: Bertrand Brasil; 2002.

28. Moretti FA, Oliveira VE, Silva EMK. Acesso a informaçốes de saúde na internet: uma questão de saúde pública? Rev Assoc Med Bras. 2012; 58(6):650-8

29. Brasil. Ministério da Saúde. Declaração de Sundsvall [Internet]. In: Brasil. Ministério da Saúde. Projeto de promoção da saúde. As cartas da promoção da saúde. Brasília: Ministério da Saúde; 2002 [citado 19 Out 2020]. Disponível em: http://bvsms.saude. gov.br/bvs/publicacoes/declaracao_sundsvall.pdf

30. Rolim LB, Cruz RSBL, Sampaio KJAJ. Participação popular e o controle social como diretriz do SUS: uma revisão narrativa. Saude Debate. 2013; 37(96):139-47.

31. Andrade JT, Costa LFA. Medicina complementar no SUS: práticas integrativas sob a luz da antropologia médica. Saude Soc. 2010; 19(3):497-508.

32. Luz MT. Comparação de representaçôes de corpo, saude, doença e tratamento em pacientes e terapeutas de homeopatia, acupuntura e biomedicina. Rio de Janeiro: UERJ/IMS; 1998.

33. Tesser CD, Luz MT. Racionalidades médicas e integralidade. Cienc Saude Colet. 2008; 13(1):195-206.

34. National Center for Complementary and Integrative Health. What is complementary, alternative or integrative health [Internet]. Bethesda: NCCAM; 2015 [citado 19 Out 2020]. Disponível em: http://nccam.nih.gov/health/whatiscam/\#1

35. Ferreira CS, Luz MT. Shen: categoria estruturante da racionalidade médica chinesa. Hist Cienc Saude Manguinhos. 2007; 14(3):863-75.

36. Kupfer P. A aculturação do Yoga. Yoga.pro [Internet]; 2014 [citado 19 Out 2020]. Disponível em: http://www.yoga.pro.br/artigos/1185/3058/a-aculturacao-do-yoga

37. Silva EDC, Tesser CD. Experiência de pacientes com acupuntura no Sistema Único de Saúde em diferentes ambientes de cuidado e (des) medicalização social. Cad Saude Publica. 2013; 29(11):2186-96. 
This study investigated meanings of autonomy and integrative and complementary practices (ICPs) assigned by health center ( $\mathrm{HC}$ ) patients and professionals and the potential contribution of ICPs to patient autonomy. We conducted a qualitative study based on data obtained from semi-structured interviews recorded and interpreted using content analysis. Eighteen individuals participated in the study, including members of a yoga group, acupuncture service users, and professionals from a HC in Florianopolis, Brazil. The findings reveal multiple understandings of patient autonomy and differences between the ICPs investigated (yoga and acupuncture). This seemed to be related to the fact that the former is more nested in the health promotion logic than the latter, which is more restricted to the clinical approach.

Keywords: Autonomy. Integrative and complementary practices. Yoga. Acupuncture.

Este estudio investigó los significados de autonomía en salud y de Prácticas Integrativas y Complementarias (PIC) atribuidos por usuarios y profesionales de un Centro de Salud (CS) y las posibles contribuciones de las PIC para la autonomía del usuario. Se realizó una investigación cualitativa, cuyas informaciones se obtuvieron por medio de entrevistas semiestructuradas, grabadas en audio e interpretadas por medio del análisis de contenido. Participaron 18 individuos, entre frecuentadores de un grupo de yoga, del servicio de acupuntura y profesionales de un CS de Florianópolis, Santa Catarina - Brasil. Los resultados revelaron entendimientos múltiples sobre autonomía en salud y diferencias entre las PIC investigadas, yoga y acupuntura, lo que pareció estar relacionado con que la primera práctica estaba más inserida en la lógica de la promoción de la salud que la segunda, más restringida al ámbito de la clínica.

Palabras clave: Autonomía. Prácticas integrativas y complementarias. Yoga. Acupuntura. 